\title{
Idosos em oficinas de informática: significação da interação na era da informação
}

\author{
Adriano Pasqualotti; ICEG/UPF; pasqualotti@upf.br \\ Dante Augusto Couto Barone; PGIE/UFRGS e PPGC/UFRGS; barone@ inf.ufrgs.br \\ Johannes Doll; PPGEDU/UFRGS; johannes.doll@ufrgs.br
}

\begin{abstract}
Resumo: Um ambiente computacional somente mudará a natureza da atividade interacionista se contemplar as mudanças que estão ocorrendo nos métodos de comunicação, pois deve favorecer o trabalho cooperativo. Para desenvolver ferramentas que viabilizem a construção do conhecimento por meio da interação é preciso conhecer os aspectos biopsicossociais e entender o potencial libertador dos processos comunicativos que se estabelecem quando os sujeitos interagem mediados pela tecnologia. Partindo de uma concepção sócio-histórica de interação social, procuramos preencher um espaço de pesquisa em relação à ação comunicativa e à significação das representações sociais sobre as tecnologias de comunicação e informação. Analisamos a tríade comunicação, tecnologia e envelhecimento, objetos de natureza distinta que advêm quando ponderam-se questões que envolvem pessoas idosas num contexto biopsicossocial. Buscamos conhecer as representações simbólicas em relação às tecnologias e analisar os sentimentos desencadeados e o significado das experiências vividas com o uso desses dispositivos.
\end{abstract}

Palavras-chave: Pessoa idosa. Rede social. Interação. Comunicação. Gerontologia.

\section{Elderly in workshops on computation: significance of the interaction in the information age}

Abstract: A computer environment will only change the nature of the interacting activity if it observes the changes that are taking place in the communication methods, for it must favor the cooperative work. In order to develop tools that enable the knowledge construction through interaction is necessary to know the biopsychosocial aspects and understand the releasing potential of the communicative processes that are established when the subjects interact mediated by technology. From a socio-historical conception of social interaction, we seek to fill a research space in relation to the communicative action and to the meaning of the social representations about the communication and information technologies. We analyzed the triad communication, technology and aging, objects of different nature that occur when issues that involve elderly people in a biopsychosocial context are pondered. We seek to know the symbolic representations in relation to the technologies and analyze the triggered feelings and the meaning of the experiences obtained through the use of these mechanisms.

Key words: Elderly people. Social network. Interaction. Communication. Gerontology.

\section{Introdução}

Conforme Rodrigues (2000, p. 29) "as pessoas não estão juntas porque fazem juntas as mesmas coisas, mas ao contrário: estão juntas porque fazem coisas diferentes e, portanto, para viver dependem das outras, que fazem coisas que elas não querem ou não são mais capazes de fazer". Nesse sentido, tanto a vida quanto a história de cada um é uma "rede" construída no coletivo (WERNECK, 2000). Em relação às pessoas idosas, esses sujeitos 
2

buscariam uma idéia de coletividade ao se agregarem nos grupos de convivência para a terceira idade. Conforme Peixoto (2003, p. 76), é uma denominação criada na França, no início da década de 1960, como conseqüência de uma política que visava à transformação da imagem dos idosos. $\mathrm{O}$ termo indica envelhecimento ativo e independente e designa a fase do ciclo da vida entre a aposentadoria e a velhice. Para a autora, "a terceira idade converte-se em uma nova etapa da vida, em que a ociosidade simboliza a prática de novas atividades, sob o signo do dinamismo". Para Costa (2007, p. 36-37), a "participação na vida social, isto é, a integração do indivíduo idoso na comunidade", dá-se por meio das possibilidades oferecidas pela própria sociedade. Entre as alternativas apresentadas às pessoas idosas, destacam-se os GTI, pois, de acordo com a autora, são "alternativas válidas de intervenção que visam ao bem-estar de pessoas maduras". Na dinâmica dos movimentos sociais, os GTI se mantêm como espaços de demandas para o exercício da cidadania, bem como para a expressão de sentimentos. Nesse contexto, de acordo com Portella (2004, p. 24), o processo do envelhecimento é muito pessoal, pois "o que está acontecendo com homens e mulheres é a descoberta de que ser participante de um GTI minimiza os problemas comuns a essa etapa da vida".

Nesse contexto, há uma multiplicação de programas para a promoção e prevenção da saúde da população idosa, ligados especialmente ao poder público, à Igreja católica e às universidades abertas. A noção de espaço público caracteriza os GTI como lugares de emancipação e promoção de cidadania (ROCHA, GOMES e LIMA FILHO, 2002). Para Sant'Anna (2000, p. 60), os GTI organizados por agências governamentais e pela iniciativa privada têm como princípio básico, por meio das propostas culturais e lazer que oferecem, ocupar o tempo na velhice como uma forma para a prevenção de doenças típicas dessa fase do clico de vida. Para a autora, "a partir desse princípio que tudo se organiza nesses grupos: passeios, festas, cursos de atualização de conhecimentos, ginásticas, etc.”. Por outro lado, grupo pode ser definido como uma comunidade politicamente organizada na qual há uma forma de sociabilidade política que possibilita o estabelecimento de relações legitimas (ARENDT, 2000). Dessa forma, se os grupos se tornarem espaços públicos para a construção da realidade, pode-se conjeturar o nascimento de um movimento social que poderá alterar o processo de velhice que se delineia (TELLES, 1990). Para Scherer-Warren (1999, p. 15), o movimento se desenvolve nas dimensões de contestação, solidariedade e proposição, porém, atualmente, há uma ênfase maior nas ações solidárias. Para o autor, a noção de sujeito social é fundamental, pois visa o estabelecimento de uma idéia de sujeito no mundo, isto é, "fala-se na construção de sujeitos, pois este se constitui nas relações sociais que incluem a autonomia ou a autocriatividade e a alteridade". De acordo com Portella (2004, p. 23), nesses grupos, "a solidariedade provém do apoio encontrado em face dos problemas que, freqüentemente, advêm do próprio envelhecimento, embora suas causas, no entender de alguns autores, distingam-se quanto ao sexo". Para Rocha, Gomes e Lima Filho (2002, p. 1034), a maior ocupação desses espaços pelas mulheres possibilitou "uma nova condição de autonomia e respeito dentro de casa". De acordo com os autores, as mulheres "ao se constituírem sujeitos de direito, no plano privado, adquirem passaporte para um exercício mais amplo, no plano coletivo”.

A probabilidade de ocorrer novas formas de relação intergeracionais aumenta se houver uma efetiva participação do idoso (ZONABEND, 1989). A participação nesses grupos é um marco na vida do idoso, pois possibilita um efetivo processo de interação com as pessoas da mesma geração (MOTTA, 1981). Já Carstensen (1995, p. 114) afirma que os idosos interagem com uma frequiência bem menor que as pessoas mais jovens, pois "o resultado mais confiável sobre o envelhecimento social é que a taxa de inter-relações sociais declina". Por outro lado, de acordo com a autora, os GTI são espaços de socialização, por isso, o ingresso nesses grupos permitiria o manejo e a criação de novas amizades. Carvalho et al. V. 6 № 1, Julho, 2008 
3

(1998, p. 115), por sua vez, entende que "a aquisição de espaços para expressar as potencialidades e experiências se fazem necessários, uma vez que o ser humano é um manancial de novas descobertas se partir do resgate de suas raízes".

\section{Materiais e Métodos}

A pesquisa é um estudo transversal de cunho quanti-qualitativo e de natureza descritiva. Analisamos os processos de apropriação e significação das TIC com um grupo de idosos do município de Passo Fundo matriculados em oficias de informática. Para desenvolver intervenções adequadas às características sociais e culturais é necessário conhecer os aspectos sociais dos idosos, bem como analisar que processos se estabelecem quando essa população interage mediada pela tecnologia, isto é, esclarecer o peso desses aspectos nas interações tecnológicas. Em relação ao objetivo geral avaliamos o significado da interação na era da informação. Em relação aos objetivos específicos, buscamos conhecer o universo das representações imagético-simbólicas dos idosos em relação às TIC, bem como analisar o significado das experiências vividas e os sentimentos desencadeados com uso desses dispositivos tecnológicos.

A pesquisa foi realizada com uma coorte de idosos vinculados aos grupos Centro Regional de Estudos e Atividades para a Terceira Idade (Creati) e Divisão de Atenção ao Idoso (Dati) matriculados em oficinas de informática. Para a definição de pessoa idosa, utilizamos o critério cronológico definido na Assembléia Mundial sobre Envelhecimento, isto é, sujeito com 60 anos ou mais (WHO, 1984; PASCHOAL, 2005). As oficinas de informática foram desenvolvidas no Laboratório Central de Informática (LCI) da Universidade de Passo Fundo (UPF). Das cinco turmas que desenvolviam atividades de informática no primeiro semestre de 2007, quatro eram do Creati e uma da Dati. Não houve aleatorização da população, isto é, todas as pessoas presentes no dia da aplicação do instrumento participaram da pesquisa. Dos mais de cem idosos matriculados nessas oficinas, 93 responderam ao instrumento. Entretanto, foram contemplados para análise aqueles respondidos por sujeitos que tinham 60 anos completos em $1^{\circ}$ de junho de 2007. Dessa forma, dos 93 sujeitos que responderam ao instrumento, apenas 49 contemplavam esse critério.

Os dados foram coletados por meio da aplicação de instrumentos, elaborados com o objetivo de colher informações sobre os processos de comunicação e interação, o uso das TIC e os espaços comunicativos. Em razão da densidade do objeto de estudo, três eixos norteadores foram definidos para a análise do problema sobre comunicação e interação: i) significação das TIC; ii) primeiras experiências com o uso das TIC; iii) percepção dos sentimentos e relacionamentos considerando o uso das TIC. A base de dados foi definida, construída e manipulada pelo SGBD phpMyAdmin 2.10.3 - ferramenta escrita em PHP para controlar a administração de dados MySQL na web.

Foram utilizados testes paramétricos e não-paramétricos para analisar as relações de dependência, independência e interdependência entre as variáveis pesquisadas. Entre os vários testes utilizados, destacam-se a análise de variância, teste qui-quadrado de aderência, análise fatorial e análise de conglomerado. Os dados foram analisados no nível de significância de $5 \%(p=0,05)$. Os dados de cunho qualitativo foram sistematizados em diferentes categorias de análise. Na busca para atingir o significado dos depoimentos, que permitisse a inferência de conhecimentos relativos aos processos comunicativos, foi utilizada a análise de conteúdo proposta por Bardin (2004). O estudo, em observância às diretrizes da resolução 196/96 do Conselho Nacional de Saúde do Ministério da Saúde, bem V. 6 № 1 , Julho, 2008 
4

como da portaria 251/97, atende às diretrizes no que se refere ao consentimento, sigilo e anonimato, benefícios e propriedade intelectual.

\section{Resultados e Discussão}

A Tabela 1 apresenta a comparação entre as estatísticas dos indicadores demográficos que utilizamos para caracterizar a amostra pesquisa com os resultados encontrados no censo de 2000 em relação às pessoas com 60 anos ou mais responsáveis pelos domicílios, nas zonas urbana e rural do Rio Grande do Sul (IBGE, 2003). Os resultados indicam diferenças significativas $(p \leq 0,05)$ para dois indicadores.

Tabela 1 - Indicadores demográficos dos idosos vinculados aos grupos Creati e Dati.

\begin{tabular}{llccc}
\hline Indicador & Categoria & $\mathrm{n}(\% \mathrm{O})$ & $\mathrm{N}(\% \mathrm{E})$ & $\mathrm{p}$ \\
\hline Sexo & Feminino & $35(76,1)$ & $611423(57,4)$ & 0,000 \\
& Masculino & $11(23,9)$ & $454061(42,6)$ & \\
Escolaridade & Menos de 4 anos & $08(17,4)$ & $217370(20,4)$ & 0,456 \\
& 4 anos ou mais & $38(82,6)$ & $848114(79,6)$ & \\
Renda familiar & Menos de 3 SM & $11(23,9)$ & $351906(56,1)$ & 0,000 \\
& 3 SM ou mais & 35(76,1) & $275451(43,9)$ & \\
\hline
\end{tabular}

$n(\% O)=$ Dado observado; $N(\% E)=$ Dado esperado; SM = Salário mínimo.

Um dos focos das pesquisas sobre o uso das TIC pelas pessoas idosas diz respeito ao processo de envelhecimento ativo, fato que se vincula, por um lado, ao relacionamento dinâmico entre as mudanças temporais da sociedade e o desenvolvimento tecnológico e, por outro, ao próprio envelhecimento humano. Nos Estados Unidos, em 2005, somente 26\% das pessoas idosas usavam computador e internet. Os dados sócio-demográficos indicavam que esse grupo etário era formado por pessoas brancas que viviam em família e que possuíam uma renda mensal e um nível educacional mais elevado que a média da população em geral (CZAJA e SCHULZ, 2006). De acordo com Czaja e Lee (2007, p. 342), "não ter acesso às novas tecnologias ou não poder usá-la na totalidade, põe cada vez mais as pessoas idosas em desvantagem no tocante às condições de viver de forma independente". Podemos verificar se as TIC estão auxiliando as pessoas idosas melhorar a qualidade de vida de duas maneiras: em primeiro lugar, os produtos e os serviços projetados devem assegurar que a maioria absoluta beneficiar-se-á dessa tecnologia; em segundo lugar, o potencial de uso para o desencadeamento de processo de interação social deve compensar os possíveis prejuízos funcionais, possibilitando que o usuário tenha uma vida independente.

De acordo com Selwyn et al. (2003, p. 568), "as tecnologias de comunicação mais acessíveis às pessoas idosas são aquelas que transmitem conteúdo em "massa', tais como telefone fixo, TV aberta e rádio". Segundo Czaja e Lee (2001, p. 114), "num futuro próximo a TV, o telefone e outros meios de comunicação tornar-se-ão integrados à informática [...] Quem não interagir por meio das tecnologias de informação estará em desvantagem". De acordo com Bronswijk, Kearns e Normie (2007, p. 130), "o aumento na capacidade de processamento computacional combina-se cada vez mais com a diminuição significativa do tamanho de componentes como o teclado e o mouse, fatores que podem excluir os usuários cuja destreza e/ou visão estejam comprometidos".

Com relação ao acesso aos dispositivos tecnológicos para o processo de comunicação e interação, todos os idosos informaram que têm TV e telefone; $98 \%$ têm rádio; $78 \%$ têm computador. Com relação ao tempo livre utilizado para participar de alguma atividade de lazer, $98 \%$ assistem TV; $78 \%$ ouvem rádio; $65 \%$ afirmaram que acessam a internet; $57 \%$ V. 6 № 1 , Julho, 2008 
5

usam o computador como passatempo e $35 \%$ para escrever ou fazer cálculos. Com relação à significação da tecnologia, para todos é um meio de comunicação e de aquisição de conhecimento; para 94\% é uma forma de participação do mundo; para 92\% é uma forma de atualização perante os outros; por outro lado, para $98 \%$ é algo a aprender, para $94 \%$ é um desafio; para $88 \%$ é um instrumento a ser dominado; por fim, para $80 \%$ é algo diferente.

Com relação às oficinas de informática, a Tabela 2 apresenta uma série de indicadores que delineia o interesse do grupo de idosos em relação a sua participação nesses encontros. Avaliamos quanto os sujeitos estariam dispostos a pagar por mês para participar das oficinas de informática; verificamos quantos encontros gostariam de ter por semana para aprender sobre informática; por fim, analisamos quantas horas por semana estariam dispostos a dedicar para consolidar por conta própria o conhecimento adquirido durante a realização da oficina de informática, bem como para ampliar a rede de amigos, utilizando o computador como uma tecnologia de interação, informação e comunicação.

Tabela 2 - Idosos avaliando a participação em oficinas de informática.

\begin{tabular}{|c|c|c|c|c|}
\hline Indicador & Categoria & $\mathrm{n}$ & $\%$ & $\%$ acumulado \\
\hline \multirow[t]{5}{*}{ Pagar para aprender } & Menos de $\mathrm{R} \$ 10,00$ & 16 & 32,7 & 32,7 \\
\hline & $\mathrm{R} \$ 10,00$ a $\mathrm{R} \$ 19,00$ & 11 & 22,4 & 55,1 \\
\hline & $\mathrm{R} \$ 20,00$ a $\mathrm{R} \$ 29,00$ & 8 & 16,3 & 71,4 \\
\hline & $\mathrm{R} \$ 30,00$ a $\mathrm{R} \$ 39,00$ & 7 & 14,3 & 85,7 \\
\hline & Mais de $\mathrm{R} \$ 40,00$ & 7 & 14,3 & 100,0 \\
\hline \multirow[t]{3}{*}{ Encontros por semana } & Um & 9 & 18,4 & 18,4 \\
\hline & Dois & 26 & 53,0 & 71,4 \\
\hline & Três & 14 & 28,6 & 100,0 \\
\hline \multirow[t]{3}{*}{ Estudos adicionais } & Menos de 10 horas & 18 & 36,7 & 36,7 \\
\hline & 10 a 19 horas & 24 & 49,0 & 85,7 \\
\hline & Mais de 20 horas & 7 & 14,3 & 100,0 \\
\hline \multirow[t]{3}{*}{ Ampliar a rede de amigos } & Menos de 10 horas & 22 & 44,9 & 44,9 \\
\hline & 10 a 19 horas & 20 & 40,8 & 85,7 \\
\hline & Mais de 20 horas & 7 & 14,3 & 100,0 \\
\hline
\end{tabular}

Com relação à auto-avaliação como aluno da oficina de informática, $78 \%$ têm iniciativa para a realização de estudos adicionais relacionados à informática e $92 \%$ estão satisfeitos com o desempenho alcançado na realização da oficina; já com relação à avaliação que os idosos realizaram das professoras, todos indicaram que elas cultivam um bom relacionamento com as pessoas que realizam a oficina de informática; $98 \%$ descreveram que as professoras dinamizam as aulas mantendo a atenção das pessoas e que expõem o conteúdo com linguagem que possibilita adequada compreensão. Já para avaliar os aspectos considerados pertinentes à oficina de informática, reunimos numa matriz orientadora os indicadores referentes aos aspectos acadêmicos sobre os quais as pessoas idosas emitiram juízo de valor e que, em seu conjunto, expressam a totalidade da avaliação da oficina de informática. Em outras palavras, a matriz foi elaborada com indicadores que caracterizam as atividades trabalhadas pelas professoras, bem como descrevem o processo pedagógico dos encontros. As três dimensões constituintes do agrupamento dos indicadores são as seguintes: conteúdo proposto, atividade desenvolvida e processo de interação e comunicação.

Por meio do coeficiente alfa $(\alpha)$ de Cronbach verificamos a congruência dos itens que compõem o instrumento que avaliou as atividades trabalhadas pelas professoras na oficina de informática. $\mathrm{O} \alpha$ de Cronbach antes da transformação dos escores brutos em escores padronizados foi igual a 0,835 (o coeficiente $\alpha$ padronizado foi igual a 0,871 ); serve, assim, V. 6 № 1, Julho, 2008 
6

como indicador de consistência do instrumento, pois esse grau de covariância dos itens entre si pode ser considerado aceitável. Para verificar a estrutura interna (validade do constructo) do instrumento, foram realizadas análises separadas para cada uma das questões. A matriz de intercorrelações indicou uma fatorização, isto é, apresentou suficiente covariância para permitir a procura de fatores. Além disso, o coeficiente de Kaiser-MeyerOlkin (KMO), que indica tal evento, foi 0,713, valor considerado médio para ser utilizado na comparação das correlações entre as variáveis. A Tabela 3 apresenta a matriz de correlação das dimensões, isto é, dos indicadores de avaliação das atividades desenvolvidas na oficina de informática após o agrupamento. Todas as dimensões apresentaram entre si correlação positiva significativa, porém a maior indicação ocorreu entre as dimensões 2 e 3 - atividade desenvolvida e processo de interação e comunicação. Isso indica que os idosos participam desses encontros com a finalidade de aprenderem estratégias para maximizar seus processos de convívio, diálogo e conversação com outras pessoas da mesma idade ou de outra geração.

Tabela 3 - Matriz de correlação das dimensões.

\begin{tabular}{cccc}
\hline Dimensões & D1 & D2 & D3 \\
\hline D1 & 1,000 & 0,611 & 0,594 \\
D2 & 0,611 & 1,000 & 0,730 \\
D3 & 0,594 & 0,730 & 1,000 \\
\hline D1 = Conteúdo proposto $;$ D2 $=$ Atividade desenvolvida $;$ D3 $=$ Processo de interação e comunicação.
\end{tabular}

Um modelo de representação de comportamento normalmente não pode ser gerado, utilizando variáveis manifestas, isto é, medidas observadas diretamente, porém seus efeitos podem ser medidos por meio de variáveis latentes, medidas não-mensuráveis calculadas a partir das variáveis manifestas. Por esse motivo, utilizamos a análise fatorial para investigar a dependência, independência e interdependência do conjunto de variáveis manifestas. Encontramos sete componentes para explicar o conjunto original de dados; esse número de fatores é suficiente, pois contem mais de $70 \%$ da variância das 21 variáveis analisadas. A Tabela 4 apresenta o resultado da ACP, bem como os autovalores maiores que um.

Tabela 4 - Resultado da análise de componentes principais.

\begin{tabular}{ccccc}
\hline Ordem & AV & $\% \mathrm{~V}$ & $\mathrm{AVa}$ & $\% \mathrm{Va}$ \\
\hline 1 & 6,6 & 31,3 & 06,6 & 31,3 \\
2 & 1,8 & 08,7 & 08,4 & 40,0 \\
3 & 1,7 & 08,3 & 10,2 & 48,3 \\
4 & 1,6 & 07,5 & 11,7 & 55,8 \\
5 & 1,3 & 06,0 & 13,0 & 61,8 \\
6 & 1,2 & 05,8 & 14,2 & 67,7 \\
7 & 1,1 & 05,4 & 15,3 & 73,0 \\
\hline AV= Autovalor $\%$ \% $=$ \% da variância $;$ AVa $a=$ Autovalor acumulado; \%Va $=\%$ da variância acumulada.
\end{tabular}

A Figura 1 apresenta o carregamento dos fatores em relação aos dados originais de avaliação das atividades desenvolvidas na oficina de informática. Os fatores mostram um agrupamento de indicadores diferente daqueles que tínhamos definido para as três dimensões. No primeiro, os resultados indicam que os idosos gostariam de trabalhar com atividades variadas, como por exemplo, edição de textos, desde que contemplassem as necessidades coletivas do grupo. Gostariam de ter controle total sobre a máquina para poder desenvolver a atividade proposta. O conteúdo deveria contemplar exercícios da cidadania, desencadear sentimentos de valorização e perrmitir comunicação com familiares. Já o segundo grupo indica que as atividades como edição de pequenos filmes, jogos de computador e criação de obras de arte devem ser desenvolvidas colaborativamente. Os 
7

desafios devem ser vinculados à realidade vivida por esses sujeitos, isto é, possibilitar socialização de experiências e permitir o desenvolvimento de processos de interação, comunicação e conversação em tempo real. Além disso, todas as atividades desenvolvidas devem ser avaliadas em relação ao aperfeiçoamento e ao julgamento do processo. Finalmente, o terceiro grupo indica que os idosos não estão interessados em comércio eletrônico, bem como em desenvolver atividades de forma individual. Além disso, indicaram que a aprendizagem não deve ser independente, isto é, não precisam ser desenvolvidas sem a ajuda do professor.

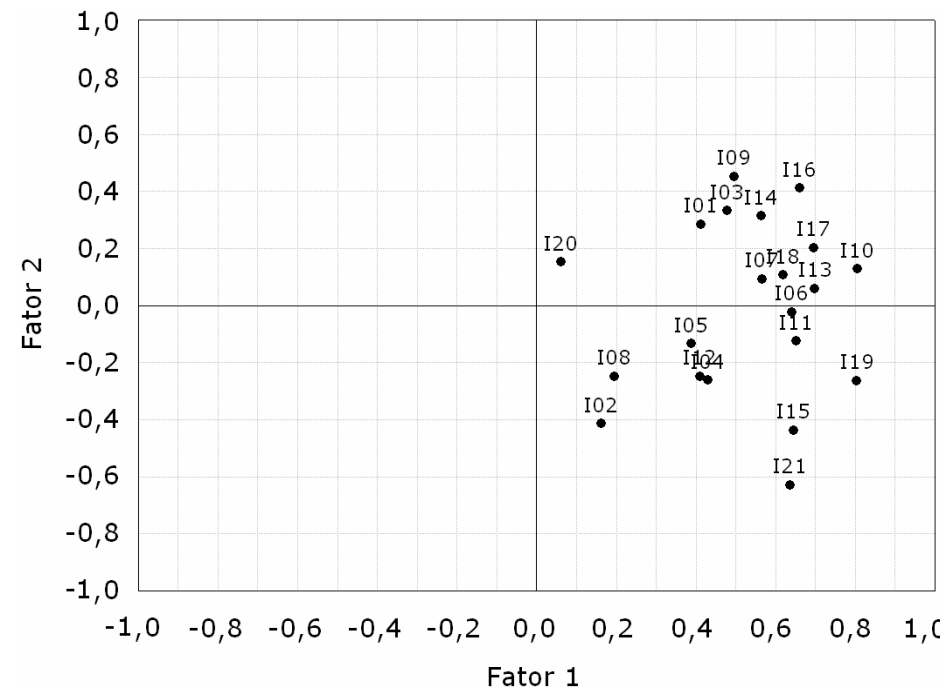

$101=$ Colaboração; $102=$ Individual; 103 = Realidade vivida; $104=$ Variedade; $105=$ Necessidades coletivas; $106=$ Exercício da cidadania; $107=$ Edição de pequenos filmes; $108=$ Aprendizagem independente; $109=$ Avaliação; $I 10=$ Interação $e$ comunicação; $111=$ Edição de textos; I12 = Controle da máquina; $I 13$ = Socialização de experiências; I14 = Jogos de computador; $115=$ Comunicação com familiares; 116 = Arranjar amigos; $117=$ Conversação em tempo real; $118=$ Criação de obras de arte; $I 19=$ Desencadear sentimentos; $120=$ Comércio eletrônico; $121=$ Fator 1

Figura 1 - Representação bidimensional de fatores em relação aos dados originais.

Para classificar as tendências de significado que os idosos atribuíram para as atividades desenvolvidas na oficina de informática utilizamos a análise hierárquica de conglomerado (MALHOTRA, 2001). Para a geração do dendograma, aplicamos o algoritmo de aglomeração definido pelo método de Ward e para a determinação das distâncias utilizamos o método Euclidiano (WARD, 1963). A Figura 2 apresenta o dendograma dos indicadores de avaliação das atividades desenvolvidas na oficina de informática. Percebemos a demarcação de três subgrupos formados com indicadores diferentes daqueles que inicialmente tínhamos definidos para as três dimensões, porém muito parecido dos determinados pela análise fatorial. 
8

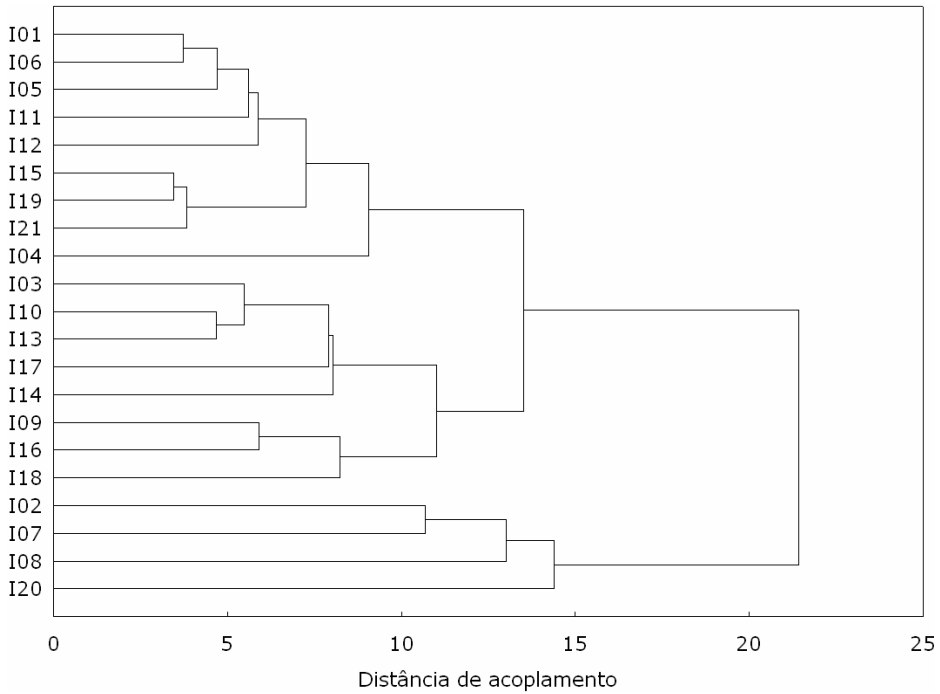

Nota: $101=$ Colaboração; $102=$ Individual; $I 03=$ Realidade vivida; $I 04$ = Variedade; $105=$ Necessidades coletivas; $106=$ Exercício da cidadania; $107=$ Edição de pequenos filmes; $108=$ Aprendizagem independente; 109 = Avaliação $: I 10=$ Interação $e$ comunicação; $I 11=$ Edição de textos; $I 12=$ Controle $d a$ máquina; 113 = Socialização de experiências; $114=$ Jogos de computador; 115 = Comunicação com familiares; 116 = Arranjar amigos; $117=$ Conversação em tempo real; $I 18$ = Criação de obras de arte; $119=$ Desencadear sentimentos; $I 20=$ Comércio eletrônico; $121=$ Sentimentos de valorização.

Figura 2 - Indicadores de avaliação das atividades desenvolvidas na oficina.

Embora a interação com o computador possa diminuir o isolamento social, o uso inadequado dessa tecnologia pode induzir o sujeito, por um lado, a abandonar a renovação ou mesmo o desenvolvimento de relacionamentos com a sua própria família e, por outro, a impossibilitar o estabelecimento de novos círculos de amizades. A utilização acéfala do computador pode trazer como conseqüência a criação de mundos próprios simulados, chegando ao ponto do sujeito preferi-los à realidade. De acordo com Turkle $(1984$, p. 19), "existe um risco de estabelecer com o computador um relacionamento que bloqueie as oportunidades para o desenvolvimento pessoal. Enquanto para algumas crianças o computador intensifica o desenvolvimento pessoal, para outras ele transforma-se num 'atoleiro"”.

A autora afirma, entretanto, que não se considera acéfalo o fato de um sujeito querer dominar a técnica de um jogo de computador. Quando o usuário interage com um programa, instrui-se em relação ao que a máquina executa, assimilando as informações acerca das estruturas e estratégias utilizadas pelo aplicativo, como por exemplo, para exibir um gráfico na tela do comutador. De acordo com Peixoto e Clavairolle (2005, p. 83), "a socialização de um objeto técnico depende, de fato, tanto da possibilidade de integração no modo de vida de cada um, quanto da sua capacidade para o adotar". Segundo Shelley, Thrane e Shulman (2006, p. 38), "a internet incentiva a participação cívica e política das pessoas idosas, pois possibilita o desenvolvimento de comunicação on-line e off-line, bem como reforça a participação igual dessas pessoas na comunidade". De acordo com Turkle (1997, p. 261), "quando atravessamos o ecrã para penetrarmos em comunidades virtuais, reconstruímos a nossa identidade do outro lado do espelho".

O poder de utilização das TIC associado ao ciberespaço reside no fato de que essas tecnologias constituem não apenas num meio de realizar tarefas, mas também numa forma de refletir as preocupações pessoais. Segundo Turkle, o uso de tecnologias como o computador oportuniza a busca de respostas para questões acerca da natureza do self, como por exemplo, em relação à vida e à intencionalidade. $\mathrm{Na}$ interação individual com o computador, os sujeitos tendem a centrar-se nas características de identidade que giram em torno do poder e do domínio; já no meio social oportunizado pelas redes informatizadas, as TIC servem de palco para a exploração de contextos sociais. Segundo Lima (2005, p. 172), "uma perspectiva meramente fenomenológica das interações [...] Seria satisfatória apenas 
9

em face dos fenômenos advindos da experiência primeira dessas interações”. Por outro lado, segundo o autor "uma perspectiva sistêmica não permite, sequer, darmos conta satisfatoriamente das novas subjetividades emergentes, que o tratamento digital da realidade potencializa". Lima afirma ainda que "as interações digitais, a partir da integração entre cultura e interface, permitem... Uma expansão desterritorializada do(s) eu(s) e da realidade em rede com os outros".

De acordo Casalegno (1999, p. 122), para Turkle o que fortalece a coesão entre os membros de uma comunidade "é a suposição de que as pessoas estão ali para nos responder... A comunidade on-line apossa-se da qualidade de reação suposta na intimidade do face a face do mundo "real"”. Para Morrell, Mayhorn e Echt (2004, p. 72), "o computador pode ser um instrumento para consolidar e aumentar as conexões sociais das pessoas idosas, especialmente a internet por ser uma fonte de informação e um mecanismo inestimável para a comunicação". Por sua vez, Carpenter e Buday (2007, p. 3020) afirmam que "os usuários de computador interagem em redes sociais mais amplas e normalmente estão mais satisfeitos com as suas circunstâncias sociais". 


\section{Conclusões}

No que diz respeito à avaliação das oficinas de informática, os dados revelam que os idosos vinculados aos GTI estariam dispostos a participar de mais de um encontro por semana e dedicar mais horas para consolidar por conta própria o conhecimento adquirido, desde que essas oficinas continuem sendo oferecidas pela universidade sem custo. Já em relação à auto-avaliação, os dados revelam que os idosos estão satisfeitos com a sua participação nesses encontros e que o processo pedagógico adotado pelas professoras é adequado. Esses resultados mostram que os objetivos traçados pelo Creati e pela Dati referente à inclusão digital estão sendo alcançados. Além disso, em relação aos aspectos acadêmicos as estatísticas indicam que os idosos participam das oficinas, especialmente com a finalidade de maximizar os processos de convívio, resultado que ratifica a importância dos programas de educação permanentes oferecidos pelas universidades abertas.

\section{Referências}

ARENDT, H. A condição humana. 10 ed. Rio de Janeiro: Forense Universitária, 2000. BARDIN, I. Análise de conteúdo. $3^{\mathrm{a}}$ ed. Lisboa: Edições Setenta, 2004.

BRONSWIJK, J. E. M. H.; KEARNS, W. D.; NORMIE, L. R. ICT infrastructures in the aging society. Gerontechnology, v. 6, n. 3, p. 129-134, Jul. 2007.

CARPENTER, B. D.; BUDAY, S. Computer use among older adults in a naturally occurring retirement community. Computers in Human Behavior, v. 23, n. 6, p. 3012-3024, Nov. 2007.

CARTENSEN, L. L. Motivação para contato social ao longo do curso de vida: uma teoria de seletividade socioemocional. In: NERI, A. L. (Org.). Psicologia do envelhecimento: temas selecionados na perspectiva de curso de vida. Campinas: Papirus, 1995, p. 111-144. CARVAlHO, A. L. et al. O idoso e a cidadania. Sensu: Pós-Graduação em Revista, v. 1, n. 1, p. 108-144, jan./jun. 1998.

CASALEGNO, F. Sherry Turkle: fronteiras do real e do virtual. Revista Famecos, Porto Alegre, n. 11, p. 117-123, dez. 1999.

COSTA, R. C. A terceira idade hoje sob a ótica do serviço social. Canoas: Ulbra, 2007. CZAJA, S. J.; LEE, C. C. The impact of the on older adults. In: CHARNESS, N.; SCHAIE, K. W. (Eds.), Impact of technology on successful aging. New York: Springer, 2001, p. 113133.

The impact of aging on access to technology. Universal Access in the Information Society, v. 5, n. 4, p. 341-349, Mar. 2007.

CZAJA, S. J.; SCHULZ, R. Innovations in technology and aging. Generations, v. 30, n. 2, p. 6-8, 2006.

FREUD, S. Obras completas de Sigmund Freud. Rio de Janeiro: Delta, [s.d.].

INSTITUTO BRASILEIRO DE GEOGRAFIA E ESTATÍSTICA - IBGE. Estatísticas do século XX. 2003. Disponível em: <http://www.ibge.gov.br/Estatisticas_secxx/ tabelas_selecionadas.xls>. Acesso em: 26 set. 2006.

LIMA, G. As redes têm centros: uma estratégia para migração da cultura pré-digital para a simbiose de redes sociais integradas em centros de atividades sociológicas e informacionais. Liinc em Revista, Rio de Janeiro, v. 1, n. 2, p. 148-176, set. 2005. 
11

MORRELL, R. W.; MAYHORN, C. B.; ECHT, K. V. Why older adults use or do not use the Internet. In: BURDICK, D. C.; KWON, S. (Eds.), Gerotechnology: research and practice in technology and aging. New York: Springer, 2004, p. 71-85.

MOTTA, E. M. Reflexos da aposentadoria sobre a questão social do idoso. Caderno da Terceira Idade, 1981.

PASCHOAL, S. M. P. Epidemiologia do envelhecimento. In: PAPALÉO NETTO, M. (Org.), Gerontologia: a velhice e o envelhecimento em visão globalizada. São Paulo: Atheneu, 2005, p. 26-43.

PEIXOTO, C. E. A Entre o estigma e a compaixão e os termos classificatórios: velho, velhote, idoso, terceira idade... In: (Org.), Velhice ou terceira idade? Estudos antropológicos sobre identidade, memória e política. 3 ed. Rio de Janeiro: FGV, 2003, p. 113-168.

PEIXOTO, C. E.; CLAVAIROLLE, F. Envelhecimento, políticas sociais e novas tecnologias. Rio de janeiro: FGV, 2005.

PORTELLA, M. R. Grupos de terceira idade: a construção da utopia do envelhecer saudável. Passo Fundo: UPF, 2004.

ROCHA, S. M.; GOMES, M. G. C.a; LIMA FILHO, J. B. O protagonismo social da pessoa idosa: emancipação e subjetividade no envelhecimento. In: FREITAS, E. V. et al. (Org.), Tratado de geriatria e gerontologia. Rio de Janeiro: Guanabara Koogan, 2002, p. 10301036.

RODRIGUES, A. T. Sociologia da educação. Rio de Janeiro: DP\&A, 2000.

SANT'ANNA, M. R. O velho no espelho: um cidadão que envelheceu. Florianópolis: UFSC, 2000.

SCHERER-WARREN, I. Cidadania sem fronteiras: ações coletivas na era da globalização. São Paulo: HUCITEC, 1999.

SELWYN, N. et al. Older adults' use of information and communications technology in everyday life. Ageing \& Society, v. 23, n. 5, p. 561-582, Sep. 2003.

SHELLEY, M. C.; THRANE, L. E.; SHULMAN, S. W. Generational differences in information technology use and political involvement. International Journal of Electronic Government Research, v. 2, n. 1, p. 36-53, Jan.-Mar. 2006.

TELLES, V. S. Espaço público e espaço privado na constituição do social: notas sobre o pensamento de Hannah Arendt. Tempo Social, v. 2, n. 1, p. 23-48, 1990.

TURKLE, S. The second self: computers and the human spirit. New York: Touchstone, 1984.

A vida no ecrã: a identidade na era digital da internet. Trad. Paulo Faria. Lisboa: Relógio D' água, 1997.

WERNECK, C. Ninguém mais vai ser bonzinho na sociedade inclusiva. $2^{\mathrm{a}}$ ed. Rio de Janeiro: WVA, 2000.

WORLD HEALTH ORGANIZATION - WHO. The uses of epidemiology in the study of the elderly. Report of a WHO Scientific Group on the Epidemiology of Aging. Geneva: WHO, 1984 (Technical Report Series, n. 706).

ZONABEND, F. Le club de loisirs du troisieme age: un rite de passage et une nouvelle forme d'echange entre generations. Dialogue, v. 104, n. 0, p. 94-103, 1989. 